\title{
Focused Ion Beam Micro Machining and Micro Assembly
}

\author{
Hongyi Yang and Svetan Rachev \\ Precision Manufacturing Centre, University of Nottingham, Nottingham
}

\begin{abstract}
The ability to manufacture and manipulate components at the microscale is critical to the development of micro systems. This paper presents the technique to manipulate micro/nano parts at the micro/nano-scale using an integrated Focused Ion Beam (FIB) system composed of scanning electron microscope, micro manipulator and gas injection system. Currently the smallest gears manufactured with traditional techniques were reported to have a module of 10 $\mu \mathrm{m}$. As a test example, in this research we applied the above integrated FIB technique and had successfully fabricated micro gears with module of $0.3 \mu \mathrm{m}$, with the precision improved for more than thirty times compared to the traditionally manufactured gears. Currently the integrated FIB technique is extended to cover the micro-assembly of devices in our centre, besides the micromanufacture procedure.
\end{abstract}

\section{Introduction}

Focused Ion Beam (FIB) machining is an ideal technique for the fabrication of nanostructured devices with sub-micro scale details; it can also be applied to mill materials that are difficult to deal with other manufacturing methods. For this reason, FIB has found wide applications in many areas, such as MEMS, optical, micro fluidic devices and so on [1]. Recently, application of FIB system has seen ever-increasing applications in micro machining and micro assembly, through integration with other powerful micro/nano facilities such as scanning electron microscopy (SEM), gas injection system (GIS) and nano-manipulator systems.

In this article, we introduce the fundamentals of a newly developed CrossBeam ${ }^{\circledR}$ system, as well as some unique capabilities of the FIB system in micro/nano machining and assembly. The FIB-based micro machining and assembly technique is a promising method for the fabrication and the assembly of complex micro-mechanical systems.

\section{Methodology}

\subsection{NVision 40 Crossbeam ${ }^{\circledR}$ System}

In the precision manufacturing centre of Nottingham University, NVision 40 CrossBeam ${ }^{\circledR}$, an integrated system combining the FIB and GIS technologies, has been put into use. Figure 1 shows the system schematics. Combined with the core technologies of GEMINI ${ }^{\circledR}$ electron beam technology, the system is the latest member of the industry proven CrossBeam ${ }^{\circledR}$ family of FIB workstations. The system also benefits from a micromanipulator and a 6-axis super eccentric specimen stage. Table 1 illustrates the capabilities and specifications of the NVison 40 system. 


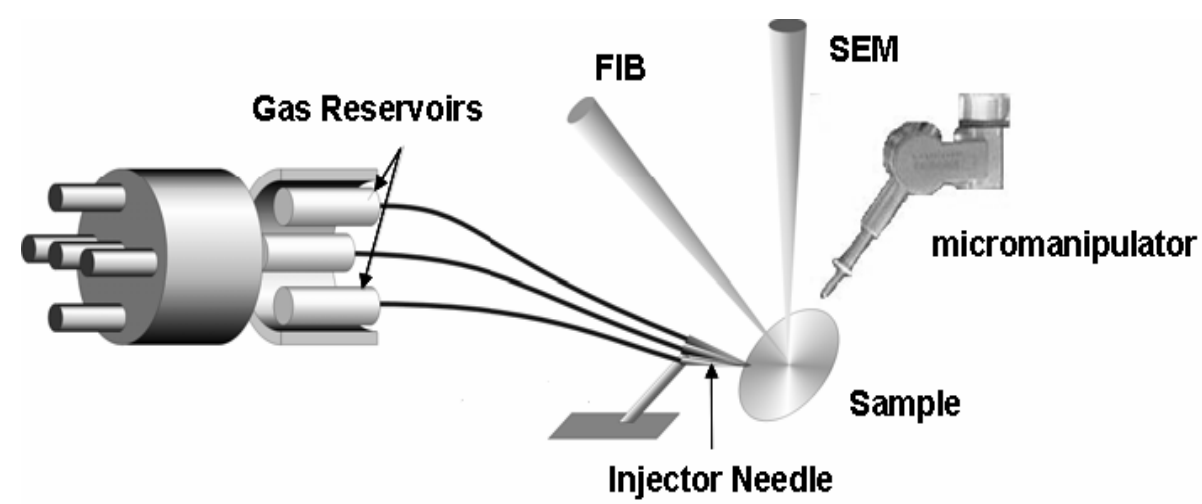

Fig. 1. Schematic of the NVision 40 CrossBeam ${ }^{\circledR}$ system

Table 1. Capabilities and specifications of the NVision 40 CrossBeam ${ }^{\circledR}$

\begin{tabular}{|c|c|c|}
\hline Capabilities & Specification & Function \\
\hline SEM (Carl Zeiss SMT) & $\begin{array}{l}\text { SEM Resolution: } 1.1 \mathrm{~nm} \text { at } 20 \mathrm{kV} ; 2.5 \\
\mathrm{~nm} \text { at } 1 \mathrm{Kv}\end{array}$ & Imaging \\
\hline $\begin{array}{l}\text { FIB (SII } \\
\text { NanoTechnology Inc.) }\end{array}$ & FIB Resolution : $4 \mathrm{~nm}$ at $30 \mathrm{kV}$ & $\begin{array}{l}\text { Milling and } \\
\text { Deposition }\end{array}$ \\
\hline GIS & $\begin{array}{l}\text { Four channel single injector GIS (Car- } \\
\left.\text { bon, platinum, insulator, water, } \mathrm{XeF}_{2}\right)\end{array}$ & $\begin{array}{l}\text { Enhanced Milling } \\
\text { and Deposition }\end{array}$ \\
\hline $\begin{array}{l}\text { Micromanipulator } \\
\text { (Kleindiek } \quad \text { nanotechnik } \\
\text { Germany) }\end{array}$ & $\begin{array}{l}\text { Motion Resolution: } 5 \mathrm{~nm} \text { in vertical } \\
\text { direction; } 3.5 \mathrm{~nm} \text { in lateral direction; } \\
0.25 \mathrm{~nm} \text { in back/ forth direction }\end{array}$ & Manipulation \\
\hline
\end{tabular}

The FIB imaging can be used for positioning the sample, but the FIB imaging has less contrast and might damage the sample surface, which needs to be taken care of during operation. In the CrossBeam operation mode both beams are turned on, and while the ion beam is milling a defined area, the SEM is used for the real-time capturing of the image of the milling process at high resolution. This enables the operator to control the milling process on a nano-scale, and thus facilitates fabricating extremely accurate cross sections and making necessary device modifications.

\subsection{Micro Machining and Micro Manipulation}

With the sputtering capability, the FIB can be used as a micro-machining tool to modify or machine materials at micro- and nano-scale accuracy. Instead of milling, materials like carbon, platinum and insulator can be deposited onto the sample surface 
when precursor gas is injected under the ion beam through the GIS system. Complex geometries can be fabricated by direct milling or deposition in a single process. During the milling/deposition process, the ion beam is applied spot-by-spot under digital control based on the geometry of the designed structure, without using masks as in conventional methods. During the feature machining and deposition process, first the feature geometry is prepared using CAD software or by importing the feature file in BMP or DXF format. Next the NVison control software converts the feature (in CAD or bitmap file format) to raster points, and then controls the beam position according to the raster points with suitable specified dwell time and current. Several factors affect the FIB system, and the optimisation of these factors has been investigated in a previous paper [2].

In this study, a slice sample was cut from the substrate and fixed on a holder. This cutting and deposition process with a micro manipulator is a typical process for the TEM sample fabrication.

To evaluate the capability of micro-manufacturing and assembly, two micro gears are fabricated as a test case study. Both the two micro gears have 15 teeth, while their nominal diameters of the pitch circle are $4.5 \mu \mathrm{m}$ or $13.5 \mu \mathrm{m}$, and the corresponding modules are $0.3 \mu \mathrm{m}$ or $0.9 \mu \mathrm{m}$.

\section{Results and Discussion}

With all the necessary capabilities integrated in one chamber, processes such as cutting, deposition and manipulation can be easily carried out with the FIB system, and the fabrication procedure can be observed in real-time through the integrated SEM capability. Figure 2 shows a TEM sample being cut and lifted by the micromanipulator and attached to the holder through the deposition process.

Micro parts or micro structure on the slab can be machined with the FIB milling in the designed profile and position. The FIB deposition glues the probe with the micro part, and the probe moves the part with high resolution to the holder or a prepared position. The part is fixed to the holder by deposition or put into a fixture without glue. The probe is then detached from the parts. Using a micro gripper, the process to glue the micro part to the probe can be avoided, thus minimising the pollution to the sample.

Compared with macro assembly, the critical challenges in the micro-assembly include the required positional precision and accuracy, the mechanics of interactions due to scaling effects, and the highly precise hand-eye coordination of the operator [3]. In conventional microscope, there is a bottle neck that limits the observation and depositing of objects with higher precision. With the FIB system, these problems can be improved with the real-time SEM high resolution imaging as well as high resolution manipulation. In the micro scale, releasing the parts becomes difficult because of the mutual forces among the parts, which are often greater than gravitational force. The deposition/cutting procedure is more advantageous over the micro gripper for carrying and releasing micro parts in this case, despite the longer operation time involved. 


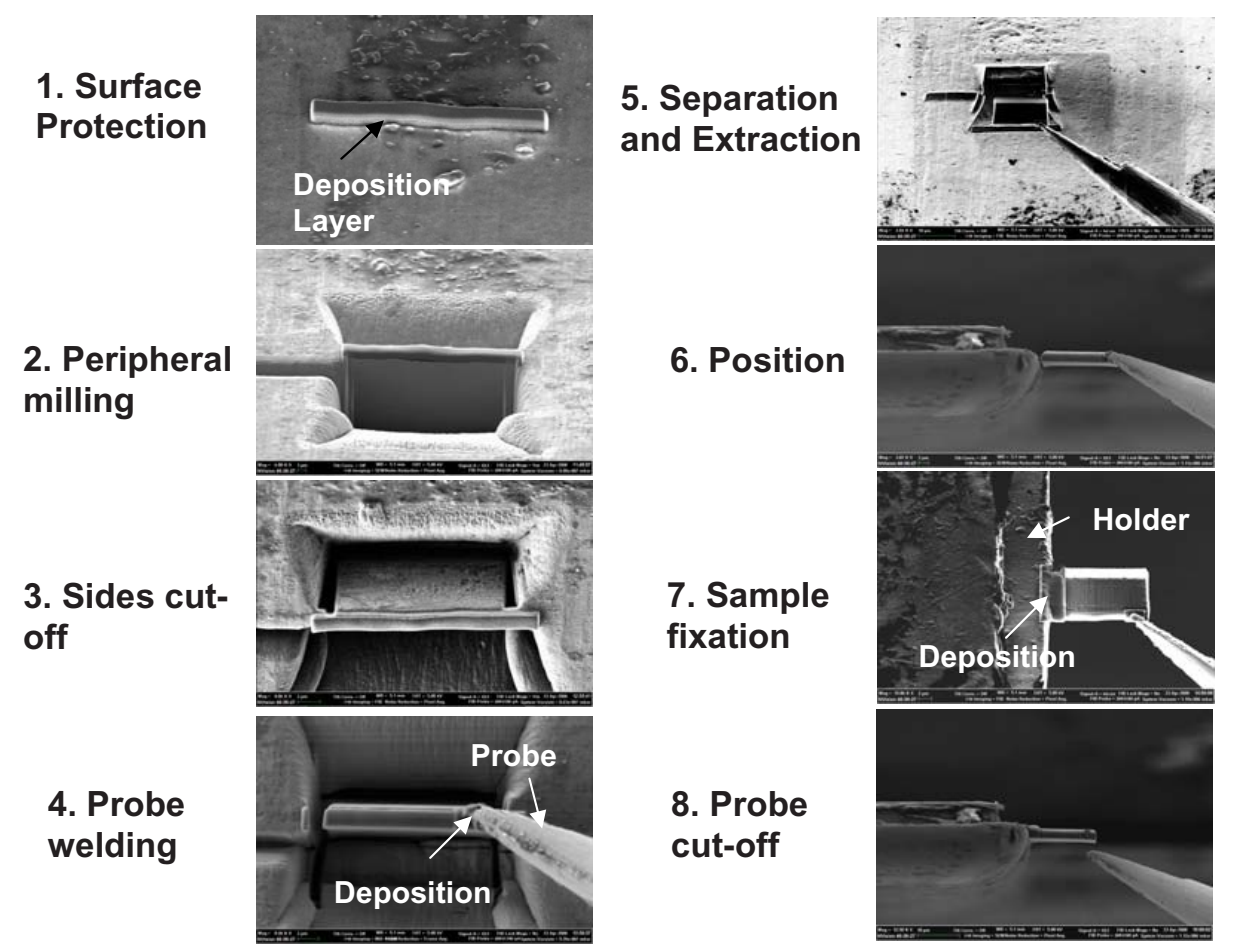

Fig. 2. Process of preparation of a TEM sample

Miniaturization of gears is the key to the development of micro devices like micromotor, which often have outside diameters of a few millimetres. To cater for the future demand for micro-gear, more and more new manufacturing methods and mass production technology are emerging. Current micro gear manufacturing methods include: hobs hobbing processing; micro wire EDM, injection molding of plastic gears; metal sintering; and other semiconductor manufacturing method like lithography or laser processing method. Ogasawara Corporation has achieved the smallest modulus of $0.01 \mathrm{~mm}$ in micro-gears with the hob cutting technique [4]. However, gears with modulus smaller than $0.01 \mathrm{~mm}$ is still at the exploratory stage.

In the current study, by fully utilising the advanced NVision 40 system we worked on fabrication of micro-gears with modulus as small as $0.3 \mu \mathrm{m}$. The superior system capability in precision manufacturing ensured the successful fabrication. Figure 3 (a) and (b) show the top view and lateral view of the fabricated micro-gear with $0.9 \mu \mathrm{m}$ modulus, and Figure 4 (a) and (b) illustrate the micro-gear with $0.3 \mu \mathrm{m}$ modulus. Currently we are working on the further development of micro-assembly procedure, to combine the fabricated micro-gears and form a practical gear motion chain. Figure 5 presents the schematic of the planed gear chain. 


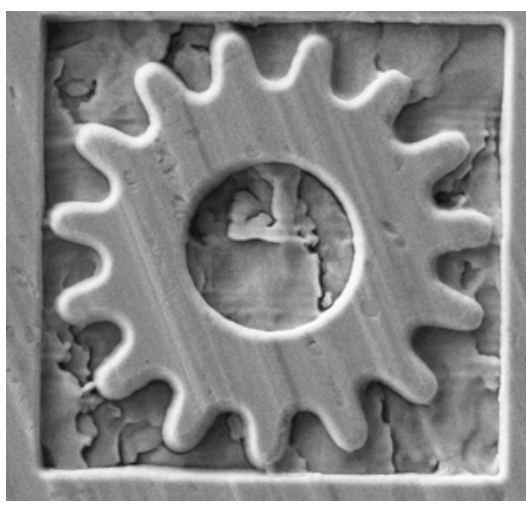

(a) Top view

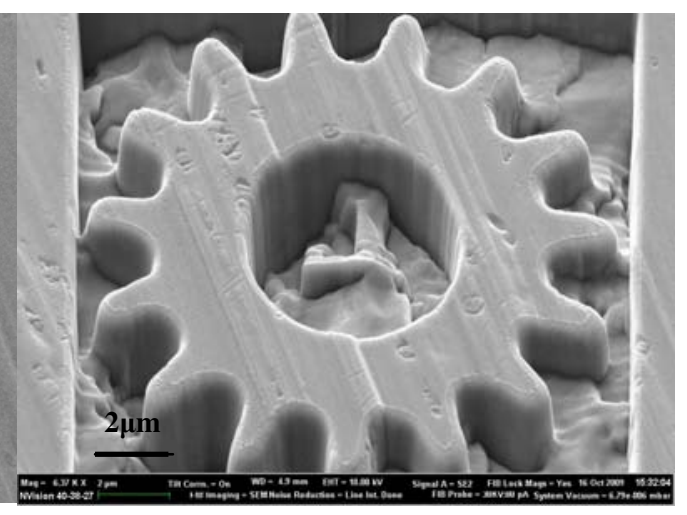

(b) Lateral view

Fig. 3. Fabricated micro gear with module of $0.9 \mu \mathrm{m}$

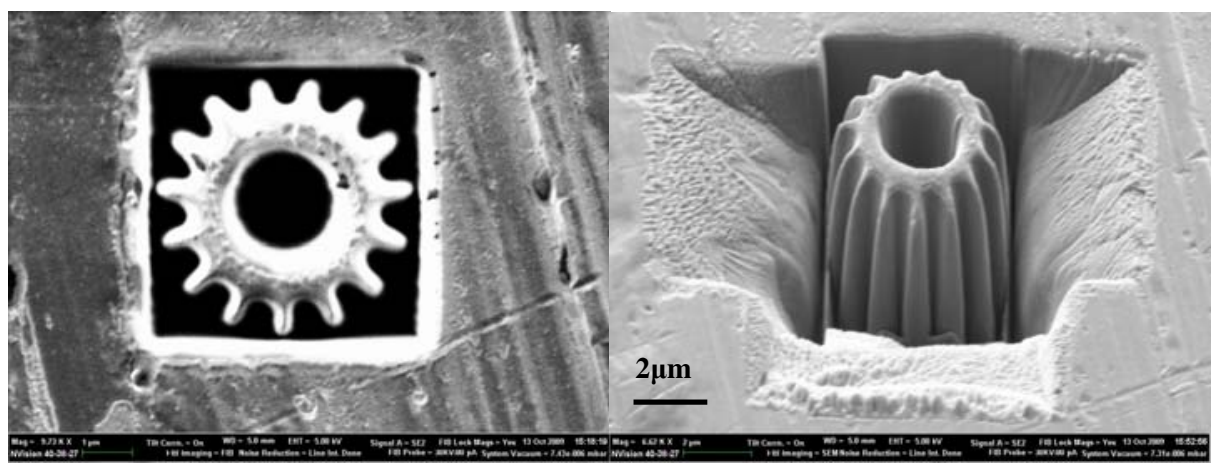

(a) Top view

(b) Lateral view

Fig. 4. Fabricated micro gear with module of $0.3 \mu \mathrm{m}$

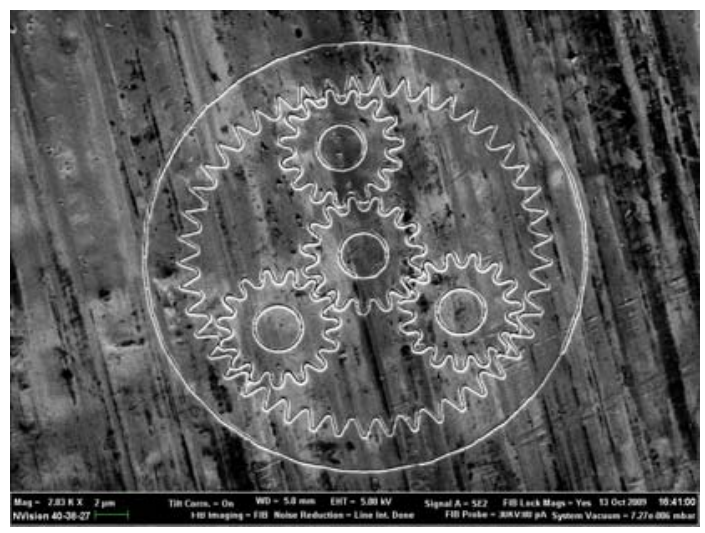

Fig. 5. Planning of micro gear assembly 


\section{Conclusion}

CrossBeam ${ }^{\circledR}$ system provides an integrated manufacturing environment for the rapidprototyping, modification and fabrication of small series of nano structures in onestop and the manipulation after the machining, which can find wide applications in nanoscience and nanotechnology practice. We have developed a micro-manufacturing procedure with superior micro-assembly capability by employing FIB milling, FIB assisted deposition, and the micro manipulation system. This micro-manufacturing procedure is a powerful technique for the fabrication and assembly of micromachines, as validated by our test fabrications so far.

\section{References}

[1] Watt, F., Bettiol, A.A., Van Kan, J.A., et al.: Ion beam lithography and nanofabrication: a review. Int. J. Nanosci. 4, 269-286 (2005)

[2] Yang, H., Ronaldo, R., Segal, J., Ratchev, S.: Focused ion beam nano machinining, Lamdmap 9th, London (2009)

[3] Tietje, C., Leach, R., Turitto, M., Ronaldo, R., Ratchev, S.: Application of a DF $\mu$ A methodology to facilitate the assembly of a micro/nano measurement device. In: Ratchev, S., Koelemeijer, S. (eds.) Micro-assembly technologies and applications. IFIP, vol. 260, pp. 5-12. Springer, Boston (2008)

[4] http://www.djwxw.com/News/HtmlPage/2006-02-16/TT_1206_1.htm 